\title{
Distal renal tubular acidosis and severe hypokalemia: a case report and review of the literature
}

\author{
George Vasquez-Rios ${ }^{1 *} \mathbb{D}$, David John Westrich Jr${ }^{1}$, Isaac Philip², John C. Edwards ${ }^{3}$ and Stephanie Shieh ${ }^{3,4}$
}

\begin{abstract}
Background: Distal renal tubular acidosis is a relatively infrequent condition with complex pathophysiology that can present with life-threatening electrolyte abnormalities.

Case presentation: We describe a case of a 57-year-old Caucasian woman with previous episodes of hypokalemia, severe muscle weakness, and fatigue. Upon further questioning, symptoms of dry eye and dry mouth became evident. Initial evaluation revealed hyperchloremic metabolic acidosis, severe hypokalemia, persistent alkaline urine, and a positive urinary anion gap, suggestive of distal renal tubular acidosis. Additional laboratory workup and renal biopsy led to the diagnosis of primary Sjögren's syndrome with associated acute tubulointerstitial nephritis. After potassium and bicarbonate supplementation, immunomodulatory therapy with hydroxychloroquine, azathioprine, and prednisone was started. Nonetheless, her renal function failed to improve and remained steady with an estimated glomerular filtration rate of $42 \mathrm{ml} / \mathrm{min} / 1.73 \mathrm{~m}^{2}$. The literature on this topic was reviewed.

Conclusions: Cases of renal tubular acidosis should be carefully evaluated to prevent adverse complications, uncover a potentially treatable condition, and prevent the progression to chronic kidney disease. Repeated episodes of unexplained hypokalemia could be an important clue for diagnosis.
\end{abstract}

Keywords: Potassium balance, Renal tubular acidosis, Autoimmune diseases, Sicca syndrome, Metabolic acidosis, Chronic kidney disease, Case report

\section{Background}

Distal renal tubular acidosis (dRTA) is characterized by a failure to acidify the urine in the distal parts of the nephron $[1,2]$. Frequently, patients present with minimal or no symptoms, which can lead to a delay in diagnosis. Progressively, it can lead to marked acid-base abnormalities, including hyperchloremic metabolic acidosis and severe hypokalemia, which can be fatal. In children, dRTA is usually associated with a genetic defect or anatomic abnormality of the urinary system [3]. In contrast, dRTA in adults is frequently related to acquired conditions such as infections, drugs, and autoimmune diseases. We describe a case of a woman with multiple

\footnotetext{
*Correspondence: george.vasquez@health.slu.edu;

george.vasquezrios@health.slu.edu

'Department of Internal Medicine, St. Louis University School of Medicine, St. Louis, MO, USA

Full list of author information is available at the end of the article
}

episodes of severe hypokalemia and weakness as the main reason for admission.

\section{Case presentation}

A 57-year-old Caucasian woman presented to our institution with severe muscle weakness, fatigue, and weight loss for the past 2 years. Her medical history included well-controlled migraines and depression, which were treated with sumatriptan and citalopram, respectively. In addition, she had chronic hypokalemia leading to multiple visits to the emergency department for muscle weakness. These episodes were treated with potassium supplementation, with only transient improvement. She denied smoking, drinking alcohol, or using recreational drugs. On further questioning, she complained about dry eyes and dry mouth for the past 5 months. Also, she mentioned unintentional weight loss of 8 pounds during the same time. Upon examination, her vital signs were within acceptable limits. She was cachectic, with marked 
temporal wasting, dry mouth, and poor dentition. No thrush was noticed. Her cardiopulmonary evaluation was unremarkable, and no organomegaly was palpated. Her neurological examination revealed decreased muscle strength in upper and lower extremities, both proximally and distally. Furthermore, her tendon reflexes were decreased throughout. However, her sensory and vibratory function was intact.

\section{Diagnostic methods}

Biochemical studies showed hyperchloremia $(122 \mathrm{mEq} / \mathrm{L})$, nonanion gap (non-AG) metabolic acidosis $\left(\mathrm{HCO}_{3}^{-}, 16\right.$ $\mathrm{mEq} / \mathrm{L}$; AG corrected for albumin, $7.8 \mathrm{mEq} / \mathrm{L}$ ), and severe hypokalemia $(2.5 \mathrm{mEq} / \mathrm{L})$. In addition, her serum creatinine $(\mathrm{Cr})$ was $1.3 \mathrm{mg} / \mathrm{dl}$ (estimated glomerular filtration rate [eGFR], $42 \mathrm{ml} / \mathrm{min} / 1.73 \mathrm{~m}^{2}$ per the Modification of Diet in Renal Disease formula [MDRD]), and her blood urea nitrogen was $16 \mathrm{mg} / \mathrm{dl}$. The remaining electrolytes, including calcium, magnesium, and phosphorus, were within normal limits. Her arterial blood gas showed pH 7.29, partial pressure of carbon dioxide $26 \mathrm{mmHg}$, and partial pressure of oxygen $134 \mathrm{mmHg}$. Her urine biochemistry revealed specific gravity 1.004 , urine osmolality 175 $\mathrm{mOsm} / \mathrm{L}$, and $\mathrm{pH}$ 7.0. On further evaluation, the patient had a high urine anion gap (UAG) of + 23 and an inappropriately high potassium-to-creatinine ratio $(\mathrm{K} / \mathrm{Cr})$ of 3.9 $\mathrm{mEq} / \mathrm{mg}$. Repeated urine studies showed persistent alkaline urine ( $\mathrm{pH}$ range, 6.5-7) with no evidence of glycosuria or phosphaturia. These findings were concerning for dRTA complicated with severe symptomatic hypokalemia. Additionally, her urine sediment was notable for sterile pyuria, as well as the presence of eosinophils, which suggested an ongoing tubulointerstitial process.

She had mild polyclonal gammopathy with predominance of immunoglobulin G (IgG) antibodies and undetectable IgG4 levels. Furthermore, antinuclear antibody titers (1:1280, speckled pattern), antibodies against Sjögren's syndrome antigen A (116.4; reference, 0-19.9), and antibodies against Sjögren's syndrome antigen B (58.3; reference, 19.9) were very high, suggesting Sjögren's syndrome (SS). The patient had no antibodies against salivary protein 1 or parotid-specific proteins. Antibodies against carbonic anhydrase (CA) type VI were negative as well. A renal biopsy was conducted, which revealed acute tubulointerstitial nephritis (TIN) with abundant eosinophils and significant lymphocytic and plasmatic cell infiltration (Fig. 1a and b). We concluded that our patient had primary SS with acute TIN.

\section{Treatment and outcome}

The patient received aggressive therapy with potassium chloride $(180 \mathrm{mEq} /$ day $)$, sodium bicarbonate $(1960 \mathrm{mg} /$ day), and amiloride ( $10 \mathrm{mg} /$ day). In addition, she was treated with immunomodulatory therapy, including hydroxychloroquine (HCQ; $300 \mathrm{mg} /$ day), azathioprine (50-100 mg/day), and a taper of prednisone. The patient tolerated the therapy and was reevaluated as an outpatient. After 2 weeks of inpatient treatment, her potassium level remained stable $(3-3.5 \mathrm{mEq} / \mathrm{dl})$, and she was minimally symptomatic. She was discharged with close follow-up.

Her strength and weight increased over the following 5 months. However, her renal function remained decreased with a serum $\mathrm{Cr}$ of $1.3-1.5 \mathrm{mg} / \mathrm{dl}$, mild hypokalemia $\left(\mathrm{K}^{+}, 3.1-3.4 \mathrm{mEq} / \mathrm{dl}\right)$, and mild metabolic acidosis $\left(\mathrm{HCO}_{3}{ }^{-}, 20 \mathrm{mEq} / \mathrm{L}\right)$, punctuated by recurrent episodes of severe hypokalemia and acidosis when she was unable to maintain the high-dose potassium and bicarbonate supplementation. Figure 3 shows the trajectories of serum potassium levels and renal function as well as the influence of medical therapy during the clinical course of the patient. Her clinical course was affected by her intermittent compliance with prednisone owing to its side effects, most importantly edema and lipodystrophy. She developed chronic kidney disease (CKD) in the setting of TIN.

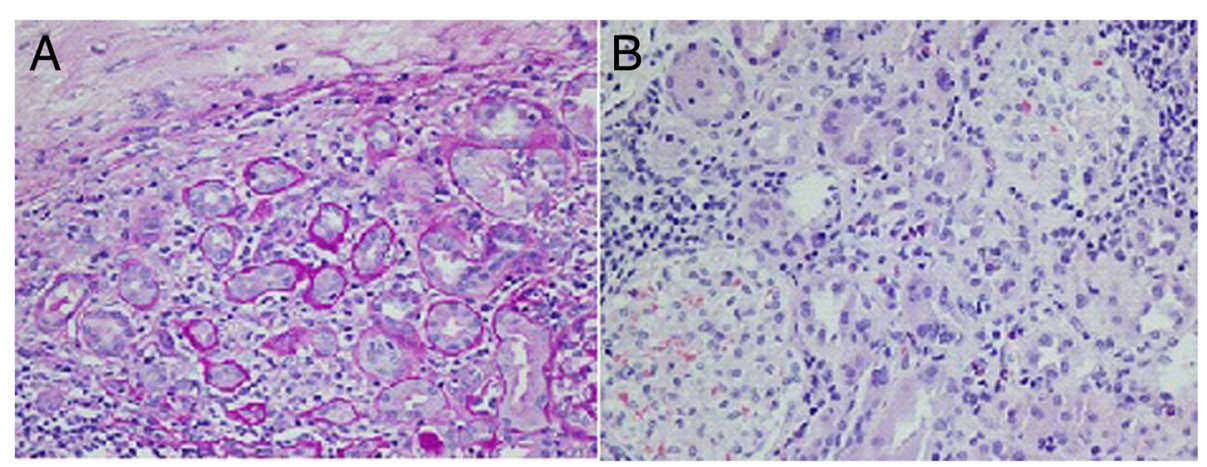

Fig. 1 a Periodic acid-Schiff stain showing tubular atrophy, interstitial fibrosis, and inflammatory infiltrate in the glomeruli. b H\&E stain showing eosinophil infiltrate in the interstitium, tubular atrophy, and intact glomeruli 


\section{Discussion}

This case report describes a patient with recurrent hypokalemia. Her clinical manifestations included severe muscle weakness in upper and lower extremities, weight loss, and marked acid-base disorders such as hyperchloremic metabolic acidosis and severe hypokalemia. Her urine studies showed persistent alkaline urine, a positive UAG, and urinary eosinophils, suggestive of dRTA and an underlying nephritis. On further evaluation, the patient was diagnosed with SS and acute TIN. She was treated with prednisone, azathioprine, and HCQ in addition to potassium and bicarbonate supplementation, which helped to maintain acceptable serum potassium levels. However, the patient's renal function failed to improve and transitioned to CKD. This is a unique case of repeated episodes of hypokalemia related to an immunological insult that ultimately induced progressive renal failure. Despite combined immunomodulatory therapy, the patient's outcomes were marginal. This case provides a physiological perspective on a poorly understood condition: TIN and SS.

Distal RTA, also known as type 1 RTA or classic RTA, is a complex entity characterized by an inability to acidify the urine; a process that occurs in the distal parts of the nephron, including the connecting tubule and the collecting duct [4]. Little is known about the prevalence of this condition in the general population. In Thailand, one study revealed that the prevalence of dRTA was $2.8 \%$, concerning for an endemic form of this disease [5]. However, the prevalence of dRTA can be as high as $22-25 \%$ in specific populations, such as in patients with osteopenia and SS [6-9]. In children, dRTA may result from genetic mutations that affect the normal acidification system, including the genes ATPVOA4 and ATP 6 V1B1, which encode the subunits A4 and B1 of the proton ATPase $\left(\mathrm{H}^{+}\right.$-ATPase), respectively, or defects in the gene SCL4A1 that encodes anion exchange proteins [10-12]. In addition, dRTA can result from an abnormality of the ureteropelvic system, such as medullary sponge kidney, obstructive uropathies, or pyelonephritis. Conversely, dRTA is frequently associated with autoimmune diseases, medications, and parathyroid disorders in the adult population $[1,2]$.

Acid secretion by the kidney can be conceptualized as having two components: (1) reclamation, which involves the reabsorption of the filtered bicarbonate load, a mechanism that is preserved in patients with dRTA; and (2) regeneration, which occurs in the distal parts of the nephron to further excrete the excess of nonvolatile acids generated from the diet. Urinary acidification and regulation of acid-base balance result from the integrated function of the collecting duct, where the transport pathways for sodium, potassium, and protons $\left(\mathrm{H}^{+}\right)$ are tightly intertwined. The cortical collecting duct is comprised of three distinct cell types that conduct very different transepithelial transport activities: principal cells, $\alpha$-intercalated cells (A-intercalated cells), and $\beta$-intercalated cells (B-intercalated cells). The principal cells are the site of electrogenic sodium reabsorption via the apical epithelial sodium channel and the basolateral sodium-potassium ATPase $\left(\mathrm{Na}^{+} / \mathrm{K}^{+}\right.$-ATPase $)$. Transport through this pathway is upregulated by aldosterone and can be limited by apical sodium delivery and urine flow. The net effect of this transport is the generation of a lumen-negative transepithelial electrical potential. Principal cells also express voltage-gated apical potassium channels that, also in concert with the basolateral $\mathrm{Na}^{+} / \mathrm{K}^{+}$-ATPase, support $\mathrm{K}^{+}$secretion. Hence, the lumen-negative electrical potential generated by sodium reabsorption is a key driving force for $\mathrm{K}^{+}$secretion to the urine.

A-intercalated cells are the site of electrogenic $\mathrm{H}^{+}$secretion that is responsible for urinary acidification. These cells express high levels of intracellular CA type II, which generates carbonic acid $\left(\mathrm{H}_{2} \mathrm{CO}_{3}\right)$ from carbon dioxide $\left(\mathrm{CO}_{2}\right)$ and water. In the intracellular compartment, $\mathrm{H}_{2} \mathrm{CO}_{3}$ dissociates to $\mathrm{H}^{+}$and a bicarbonate ion $\left(\mathrm{HCO}_{3}{ }^{-}\right)$. The proton is secreted into the lumen across the apical membrane via the $\mathrm{H}^{+}$-ATPase, whereas $\mathrm{HCO}_{3}{ }^{-}$exits across the basolateral membrane in exchange for chloride via the chloride-bicarbonate exchanger (AE1). Furthermore, chloride recycles in the basolateral aspect of the cell through a chloride channel. Thus, A-cells dissipate the lumen-negative potential generated by sodium reabsorption through the secretion of both $\mathrm{H}^{+}$and $\mathrm{K}^{+}$, a unique feature of the distal regulation of acid load. B-intercalated cells are involved in $\mathrm{HCO}_{3}{ }^{-}$secretion and $\mathrm{K}^{+}$reabsorption and are not discussed further here. Figure 2 shows some of the main functions of the principal, A-intercalated, and B-intercalated cells.

The most common form of dRTA is due to selective failure of activity or expression of the $\mathrm{H}^{+}$-ATPase. The decreased transit through the proton pump inhibits urine acidification and reduces the electrical dissipation of the membrane potential. The latter has been suspected to be a driving force for $\mathrm{K}^{+}$secretion and eventual potassium wasting in previous studies [13-17]. Norgett et al. [18] reproduced this hypothesis in knockout mice with deficient expression of the gene ATP6VOA4 and found that these mice developed severe hyperchloremic metabolic acidosis, hypokalemia, and early nephrocalcinosis when challenged with acid load, features encountered in patients with severe dRTA. As hypokalemia progresses, storage tissues such as the skeletal muscle compensate by releasing $\mathrm{K}^{+}$to the extracellular compartment, for which laboratory data may fail to uncover a $\mathrm{K}^{+}$imbalance. However, a serum $\mathrm{K}^{+}<3 \mathrm{mEq} / \mathrm{L}$ is related to a total body deficit of $>200 \mathrm{mEq}$, which varies with weight [19]. Patients with 


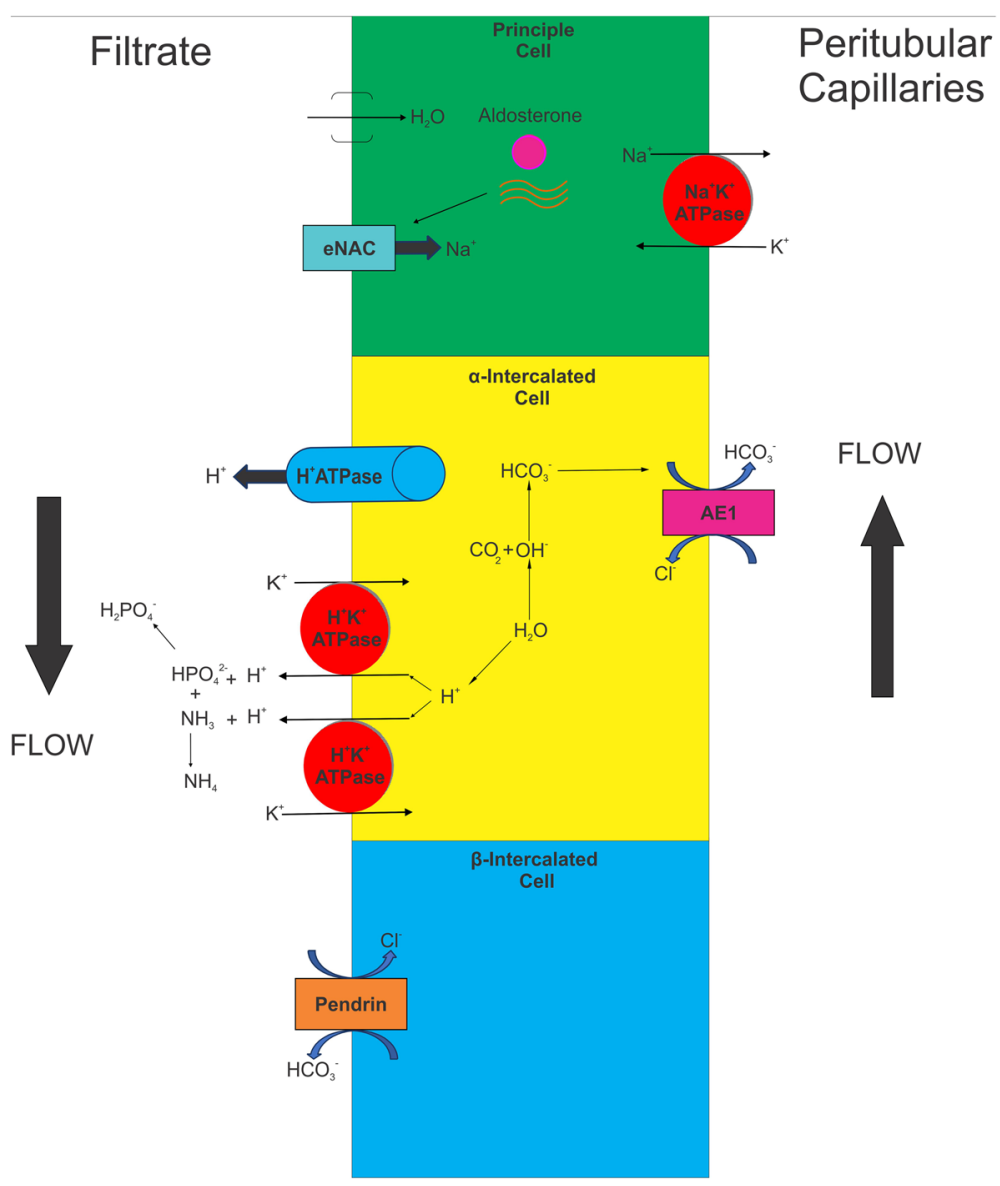

Fig. 2 Main physiological functions of the principal cell, a-intercalated cell, and $\beta$-intercalated cell. AE1 Anion exchanger 1, eNAC Epithelial sodium channel

SS and dRTA can present life-threatening complications owing to massive intracellular potassium depletion, including rhabdomyolysis, respiratory paralysis, or malignant arrhythmias [13, 14, 20, 21].

The exact mechanism by which SS can induce dRTA remains unclear. However, previous studies evidenced a downregulated expression of the vacuolar $\mathrm{H}^{+}$-ATPase in the A-intercalated cells in patients with SS with concomitant underexpression of AE1 (pendrin) in the B-intercalated cells. It is hypothesized that the reduced secretion of $\mathrm{H}^{+}$is the primary dysfunction in SS, whereas the underregulation of pendrin is a compensation to suppress $\mathrm{HCO}_{3}{ }^{-}$secretion and prevent further acidosis $[13,14,17]$. Despite the presence of $\mathrm{H}^{+}$-ATPase and AE1 in other parts of the nephron, patients with SS present selective underexpression of these proteins in the collecting duct. Furthermore, patients with SS can also develop antibodies against components of the cellular membrane or intracellular proteins. Devuyst et al. [15] found IgG autoantibodies in a patient with SS that reacted against A-intercalated cells of a human control kidney. However, the target protein was not identified.
Additional studies have identified antibodies against enzymes involved in the acid excretion system and bicarbonate generation, including CA type II, CA type IV, and CA type VI [22-26]. It is not clear whether these antibodies are part of the pathogenesis of SS or if they result from the exposure of intracellular epitopes to the immune system during tubular damage $[13,14,22,27]$. Our patient tested negative for CA-VI specific antibodies. However, a prospective evaluation is needed because these antibodies may appear over the course of disease.

Our patient was treated with $\mathrm{K}^{+}$and sodium bicarbonate supplementation to correct her acid-base imbalance. She also received amiloride as recent literature suggests that patients with severe disease may respond to this therapy [28]. Amiloride inhibits electrogenic sodium transport through the epithelial sodium channel in the principal cells and thus decreases the driving forces for electrogenic potassium secretion [28]. On follow-up, she maintained mild hypokalemia $\left(\mathrm{K}^{+}, 3.1-3.4 \mathrm{mEq} / \mathrm{L}\right)$ as well as mild metabolic acidosis $\left(\mathrm{HCO}_{3}{ }^{-}, 19-23 \mathrm{mmol} / \mathrm{L}\right)$. No further improvement was seen in these clinical parameters after the introduction 
of immunomodulatory therapy. Discontinuation of prednisone was related to worsening renal function as described in Fig. 3.

Up to $71 \%$ of the patients with SS and renal involvement may develop acute or chronic TIN, whereas cryoglobulinemic glomerulonephritis and focal segmental glomerulosclerosis are infrequent, accounting for $<5 \%$ of the cases [29]. Our patient presented an acute form of TIN with significant eosinophil/plasmatic cell infiltration and minimal tubular atrophy, which has been described elsewhere [30]. Figures 1 and 2 present the patient's renal biopsy with characteristic findings described in SS. Some studies have reported specific histological findings in patients with SS and TIN, including lymphocytic infiltrate with predominance of T-helper cell populations, most prominently the Th-17 subpopulation [31]. These findings have also been noted in biopsy samples of the salivary gland of patients with SS, suggesting that blunting the primary immune response affecting salivary glands could also attenuate the inflammation in the kidneys. Thus, several reports extrapolate the therapy for patients with SS without renal disease to those with SS and renal involvement. To the best of our knowledge, very few studies have evaluated the response to immunomodulatory therapy in biopsy-proven TIN secondary to SS [29, 30]. Evans et al. [30] included 12 patients treated with a course of prednisone associated with mycophenolate mofetil (11 of 12) or azathioprine (1 of 12) to effectively affect both B-cell and T-cell populations. Interestingly, patients presented a significant response evidenced in their serum $\mathrm{Cr}$ levels and eGFR. Maripuri et al. [29] demonstrated that a mixed population including patients with SS and membranous proliferative glomerulonephritis would effectively respond to HCQ, cyclophosphamide, and rituximab. However, such therapy is difficult to reproduce in clinical practice, based on the low power of the study and the clinical characteristics of the participants.

While the immunomodulatory effect of HCQ relays in suppressing Toll-like receptors in a wide range of cells, azathioprine is an antimetabolite that inhibits synthesis of DNA, RNA, and proteins predominantly in T cells and B cells. Although both medications have been used for the management of this condition, outcomes have been variable in the literature. After 5 months of follow-up, our patient's renal function was steady with an eGFR of 38-42 $\mathrm{ml} / \mathrm{min} / 1.73 \mathrm{~m}^{2}$ (MDRD formula). She was dependent on high-dose potassium and bicarbonate supplementation to maintain her electrolyte homeostasis, which suggests that tubulointerstitial injuries in SS can have minimal response to standard immunomodulatory therapy. This group of patients benefits from follow-up and further management to prevent progression of CKD to end-stage renal disease [32].

\section{Conclusions}

This case highlights the importance of an early detection and physiology-based approach to dRTA. Accurate characterization of this condition is pivotal to uncover an underlying disease, tailor a specific therapy, and prevent

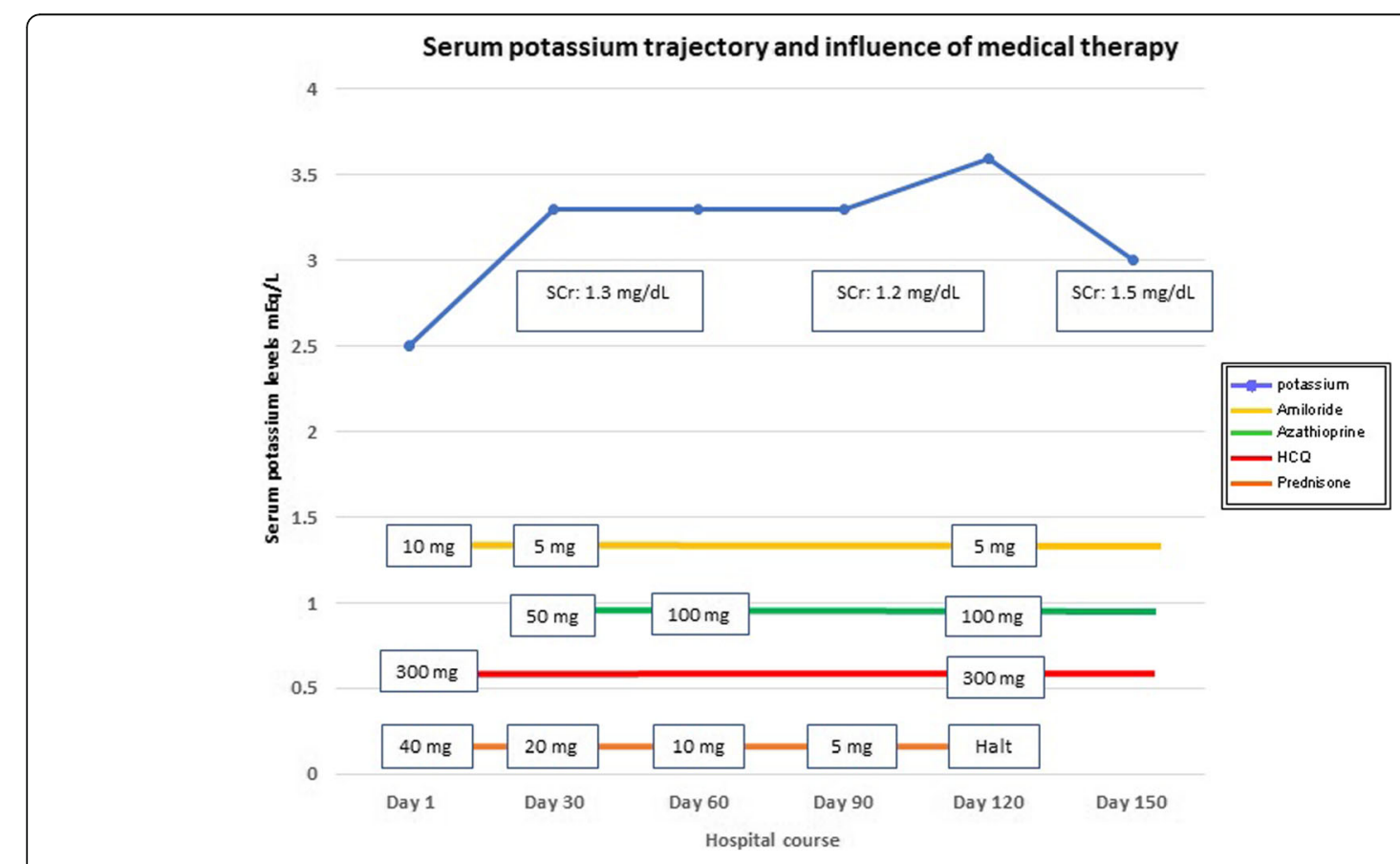

Fig. 3 Serum potassium levels, medical therapy implemented, and clinical course of the patient 
further renal function decline. Episodes of symptomatic hypokalemia could be a clue for diagnosis and should be carefully addressed to prevent life-threatening complications. Evaluating the renal response to immunomodulatory therapy in SS is of paramount interest as it can lead to a progressive decline in renal function.

\section{Abbreviations}

AG: Anion gap; CA: Carbonic anhydrase; CKD: Chronic kidney disease; Cr: Creatinine; dRTA: Distal renal tubular acidosis; eGFR: Estimated glomerular filtration rate; HCQ: Hydroxychloroquine; IgG: Immunoglobulin G; MDRD: Modification of Diet in Renal Disease; SS: Sjögren's syndrome; TIN: Tubulointerstitial nephritis; UAG: Urine anion gap

\section{Acknowledgements}

The authors express their gratitude to Dr. David Brink and the Pathology Department at St. Louis University School of Medicine for assistance with clinical pathological images.

\section{Funding}

None.

\section{Availability of data and materials}

All data, images, and results are available from the corresponding author on reasonable request.

\section{Authors' contributions}

GVR drafted the manuscript. GVR conducted the literature review. GVR, DJW, JCE, and SS were part of the medical team responsible for the care of the patient. DJW, IP, JCE, and SS evaluated the patient's results and outcomes and provided valuable technical and intellectual support to this report. JCE and SS provided expert consultation during the management of the patient and elaboration of the manuscript. All the authors made substantial contributions to the manuscript, critically reviewed the content, and accepted the final version of it.

\section{Ethics approval and consent to participate}

The CARE case report guidelines were thoroughly followed to present this case report.

\section{Consent for publication}

Written informed consent was obtained from the patient for publication of this case report and any accompanying images. A copy of the written consent is available for review by the Editor-in-Chief of this journal.

\section{Competing interests}

The authors declare that they have no competing interests.

\section{Publisher's Note}

Springer Nature remains neutral with regard to jurisdictional claims in published maps and institutional affiliations.

\section{Author details}

${ }^{1}$ Department of Internal Medicine, St. Louis University School of Medicine, St. Louis, MO, USA. ${ }^{2}$ St. Louis University School of Medicine, St. Louis, MO, USA. ${ }^{3}$ Nephrology Division, Department of Internal Medicine, St. Louis University, St. Louis, MO, USA. ${ }^{4}$ Division of Nephrology, VA St. Louis Health Care System, St. Louis, MO, USA.

Received: 4 December 2018 Accepted: 15 March 2019 Published online: 26 April 2019

\section{References}

1. Both T, Zietse R, Hoorn EJ, van Hagen PM, Dalm VA, van Laar JA, et al. Everything you need to know about distal renal tubular acidosis in autoimmune disease. Rheumatol Int. 2014;34(8):1037-45.

2. Yaxley J, Pirrone C. Review of the diagnostic evaluation of renal tubular acidosis. Ochsner J. 2016;16(4):525-30.
3. Agarwal A, Kumar P, Gupta N. Pediatric Sjogren syndrome with distal renal tubular acidosis and autoimmune hypothyroidism: an uncommon association. CEN Case Rep. 2015;4(2):200-5.

4. Bagga A, Sinha A. Evaluation of renal tubular acidosis. Indian J Pediatr. 2007; 74(7):679-86.

5. Nimmannit S, Malasit P, Susaengrat W, Ong-Aj-Yooth S, Vasuvattakul S, Pidetcha $P$, et al. Prevalence of endemic distal renal tubular acidosis and renal stone in the northeast of Thailand. Nephron. 1996;72(4):604-10.

6. Pongchaiyakul C, Domrongkitchaiporn S, Stitchantrakul W, Chailurkit LO, Rajatanavin R. Incomplete renal tubular acidosis and bone mineral density: a population survey in an area of endemic renal tubular acidosis. Nephrol Dial Transplant. 2004;19(12):3029-33.

7. Weger W, Kotanko P, Weger M, Deutschmann H, Skrabal F. Prevalence and characterization of renal tubular acidosis in patients with osteopenia and osteoporosis and in non-porotic controls. Nephrol Dial Transplant. 2000; 15(7):975-80.

8. Both T, Hoorn EJ, Zietse R, van Laar JA, Dalm VA, Brkic Z, et al. Prevalence of distal renal tubular acidosis in primary Sjogren's syndrome. Rheumatology (Oxford). 2015:54(5):933-9.

9. Duffles Amarante GB, Zotin MC, Rocha E, Delgado AG, Leite M Jr, Gomes CP. Renal tubular dysfunction in patients with primary Sjogren syndrome. Clin Nephrol. 2014;81(3):185-91.

10. Besouw MTP, Bienias M, Walsh P, Kleta R, Van't Hoff WG, Ashton E, et al. Clinical and molecular aspects of distal renal tubular acidosis in children. Pediatr Nephrol. 2017;32(6):987-96.

11. Palazzo V, Provenzano A, Becherucci F, Sansavini G, Mazzinghi B, Orlandini V, et al. The genetic and clinical spectrum of a large cohort of patients with distal renal tubular acidosis. Kidney Int. 2017;91(5):1243-55.

12. Ashton EJ, Legrand A, Benoit V, Roncelin I, Venisse A, Zennaro MC, et al. Simultaneous sequencing of 37 genes identified causative mutations in the majority of children with renal tubulopathies. Kidney Int. 2018;93(4):961-7.

13. Cohen EP, Bastani B, Cohen MR, Kolner S, Hemken P, Gluck SL. Absence of $\mathrm{H}^{+}$-ATPase in cortical collecting tubules of a patient with Sjogren's syndrome and distal renal tubular acidosis. J Am Soc Nephrol. 1992;3(2): 264-71

14. DeFranco PE, Haragsim L, Schmitz PG, Bastani B. Absence of vacuolar $\mathrm{H}^{+}$-ATPase pump in the collecting duct of a patient with hypokalemic distal renal tubular acidosis and Sjogren's syndrome. J Am Soc Nephrol. 1995;6(2):295-301.

15. Devuyst $\mathrm{O}$, Lemaire M, Mohebbi N, Wagner CA. Autoantibodies against intercalated cells in Sjogren's syndrome. Kidney Int. 2009;76(2):229.

16. Tzioufas AG, Tatouli IP, Moutsopoulos HM. Autoantibodies in Sjogren's syndrome: clinical presentation and regulatory mechanisms. Presse Med. 2012:41(9 Pt 2):e451-60.

17. Kim HY, Kim SS, Bae EH, Ma SK, Kim SW. Decreased renal expression of $\mathrm{H}^{+}$-ATPase and pendrin in a patient with distal renal tubular acidosis associated with Sjogren's syndrome. Intern Med. 2015;54(22):2899-904.

18. Norgett EE, Golder ZJ, Lorente-Canovas B, Ingham N, Steel KP, Karet Frank FE. Atp6r0a4 knockout mouse is a model of distal renal tubular acidosis with hearing loss, with additional extrarenal phenotype. Proc Natl Acad Sci U S A. 2012;109(34):13775-80.

19. Asmar A, Mohandas R, Wingo CS. A physiologic-based approach to the treatment of a patient with hypokalemia. Am J Kidney Dis. 2012:60(3):492-7.

20. Garza-Alpirez A, Arana-Guajardo AC, Esquivel-Valerio JA, Villarreal-Alarcon MA, Galarza-Delgado DA. Hypokalemic paralysis due to primary Sjogren syndrome: case report and review of the literature. Case Rep Rheumatol. 2017;2017:7509238.

21. Cherif E, Ben Hassine L, Kechaou I, Khalfallah N. Hypokalemic rhabdomyolysis: an unusual presentation of Sjogren's syndrome. BMJ Case Rep. 2013;2013:bcr2013201345.

22. Takemoto F, Hoshino J, Sawa N, Tamura Y, Tagami T, Yokota M, et al. Autoantibodies against carbonic anhydrase II are increased in renal tubular acidosis associated with Sjogren syndrome. Am J Med. 2005 118(2):181-4

23. Krishnan D, Pan W, Beggs MR, Trepiccione F, Chambrey R, Eladari D, et al. Deficiency of carbonic anhydrase $\|$ results in a urinary concentrating defect. Front Physiol. 2017:8:1108.

24. Nishimori I, Miyaji E, Morimoto K, Kohsaki T, Okamoto N, Onishi S. Diminished cellular immune response to carbonic anhydrase $\|$ in patients with Sjogren's syndrome and idiopathic chronic pancreatitis. JOP. 2004;5(4):186-92. 
25. De Langhe E, Bossuyt X, Shen L, Malyavantham K, Ambrus JL, Suresh L. Evaluation of autoantibodies in patients with primary and secondary Sjogren's syndrome. Open Rheumatol J. 2017;11:10-5.

26. Pertovaara M, Bootorabi F, Kuuslahti M, Pasternack A, Parkkila S. Novel carbonic anhydrase autoantibodies and renal manifestations in patients with primary Sjogren's syndrome. Rheumatology (Oxford). 2011;50(8):1453-7.

27. Konishi K, Hayashi M, Saruta T. Renal tubular acidosis with autoantibody directed to renal collecting-duct cells. N Engl J Med. 1994;331(23):1593-4.

28. Oguejiofor P, Chow R, Yim K, Jaar BG. Successful management of refractory type 1 renal tubular acidosis with amiloride. Case Rep Nephrol. 2017:2017:8596169.

29. Maripuri S, Grande JP, Osborn TG, Fervenza FC, Matteson EL, Donadio JV, et al. Renal involvement in primary Sjogren's syndrome: a clinicopathologic study. Clin J Am Soc Nephrol. 2009;4(9):1423-31.

30. Evans RD, Laing CM, Ciurtin C, Walsh SB. Tubulointerstitial nephritis in primary Sjogren syndrome: clinical manifestations and response to treatment. BMC Musculoskelet Disord. 2016:17:2.

31. Rosenberg ME, Schendel PB, McCurdy FA, Platt JL. Characterization of immune cells in kidneys from patients with Sjogren's syndrome. Am J Kidney Dis. 1988;11(1):20-2.

32. Liu BC, Tang TT, Lv LL, Lan HY. Renal tubule injury: a driving force toward chronic kidney disease. Kidney Int. 2018;93(3):568-79.

Ready to submit your research? Choose BMC and benefit from:

- fast, convenient online submission

- thorough peer review by experienced researchers in your field

- rapid publication on acceptance

- support for research data, including large and complex data types

- gold Open Access which fosters wider collaboration and increased citations

- maximum visibility for your research: over $100 \mathrm{M}$ website views per year

At $\mathrm{BMC}$, research is always in progress.

Learn more biomedcentral.com/submissions 